\title{
Cryptogenetic multifocal ulcerous stenosing enteritis: an atypical type of vasculitis or a disease mimicking vasculitis
}

\author{
G Perlemuter, L Guillevin, P Legman, L Weiss, D Couturier, S Chaussade
}

\section{tract \\ Backgroundlaims-Cryptogenetic multi-} focal ulcerous stenosing enteritis unknown. The aim of this study was to describe the clinical spectrum of CMUSE, to determine the origin and pathophysiology of the disease, and to propose a treatment strategy. Methods-A total of 220 French gastroenterology departments were contacted to review patients with unexplained small bowel strictures. Of 17 responses, 12 corresponded to a diagnosis of CMUSE. These patients were hospitalised between 1965 and 1993 and their medical records
were reviewed.

Results-All patients (mean age 42.1 (4.4) years) had intestinal and five had extraintestinal symptoms (peripheral neuropathy, buccal aphthae, sicca syndrome, hypertension). One patient had pair gene deletion). Two to 25 (mean 8.3 (1.9)) small intestine strictures were found. Stenoses of the large jejunoileal arteries were observed on two and aneurysms on three of five mesenteric angiograms. Despite surgery, symptoms recurred in seven of 10 patients and strictures in four. Steroid therapy was effective but caused dependence. One untreated patient died. Small bowel pathology showed superficial ulceration of the mucosae and submucosae, and an inflammatory infiltrate made of neutrophils and eosinophils.

Conclusions-CMUSE is an independent entity characterised by steroid sensitive inflammation of the small bowel which often recurs after surgery. CMUSE may be related to a particular form of polyarteritis nodosa with mainly intestinal expression or with an as yet unclassified vasculitis.

(Gut 2001;48:333-338)

Keywords: cryptogenetic multifocal ulcerous stenosing enteritis; vasculitis; small intestine

The origin and pathophysiology of chronic multiple ulcerations of the small bowel are not well established. Jeffries and colleagues ${ }^{1}$ reported a syndrome termed chronic ulcerative non-granulomatous jejunitis. This syndrome was characterised by chronic diarrhoea, altera- tion in general well being, multiple jejunal ulcerations, and total or subtotal villous atrophy. Another syndrome, characterised by intermittent bouts of intestinal obstruction, ulcerative stenoses of the small bowel relapsing after surgical resection, and steroid sensitivity was identified by Debray and colleagues. ${ }^{2}$ This syndrome was termed cryptogenetic multifocal ulcerous stenosing enteritis (CMUSE). To date, only 17 cases of CMUSE have been reported. ${ }^{2-11}$ In our first published case, ${ }^{11}$ we suggested that this disease may be caused by vasculitis related to polyarteritis nodosa. Since our first case we have studied 11 other patients suffering from CMUSE. The aim of this study was to clarify the clinical spectrum of CMUSE, to determine the origin and pathophysiology of the disease, and to propose a treatment strategy.

\section{Materials and methods}

In July 1993, we sent a letter to all gastroenterology departments of general and university hospitals in France asking them to review all medical files of patients with unexplained stenoses of the small bowel. Initially, 220 letters were sent. We received 17 responses. A detailed questionnaire was then sent to these 17 departments. The questionnaire included items on the general examination, digestive and extradigestive clinical features, laboratory findings, radiology, endoscopic examination, and isotope scan. Digestive items included abdominal pain, vomiting, diarrhoea, melena, constipation, and occlusion. Extradigestive items included rheumatological, cardiac, neurological, dermatological, and pulmonary features. Laboratory data were full blood count, erythrocyte sedimentation rate, $\mathrm{C}$ reactive protein, liver function tests, creatinine, mid stream urine, autoantibodies, viral serologies (hepatitis $B$ virus, hepatitis $C$ virus, and human immunodeficiency virus), and complement activity. Gastrointestinal tract investigations consisted of gastroscopy, colonoscopy, small bowel series, coeliac and mesenteric angiography, and bowel isotope scan using ${ }^{99 \mathrm{~m}} \mathrm{Tc}$ hexamethyl propylene amine oxime (HMPAO) labelled leucocytes. Number of laparotomies and outcome, number of strictures, corticosteroid treatment, corticosteroid sensitivity, and other attempted treatments were documented. Patients having diseases known to cause strictures of the small bowel (Crohn's disease,

Abbreviations used in this paper: CMUSE, cryptogenetic multifocal ulcerous stenosing enteritis; HMPAO, hexamethyl propylene amine oxime. 
Table 1 Digestive characteristics of patients with cryptogenetic multifocal ulcerous stenosing enteritis

\begin{tabular}{|c|c|c|c|c|c|c|c|c|c|c|c|c|}
\hline $\begin{array}{l}\text { Case } \\
\text { No }\end{array}$ & $\begin{array}{l}\text { Sexlage } \\
\text { (y) }\end{array}$ & $\begin{array}{l}\text { Interval } \\
\text { between first } \\
\text { symptoms } \\
\text { and stricture } \\
\text { diagnosis } \\
(y)\end{array}$ & $\begin{array}{l}\text { Digestive } \\
\text { involvement }\end{array}$ & $\begin{array}{l}\text { Location } \\
\text { of } \\
\text { strictures }\end{array}$ & $\begin{array}{l}\text { No of } \\
\text { strictures }\end{array}$ & $\begin{array}{l}{ }^{99 m} T c \\
\text { HMPAO } \\
\text { labelled } \\
\text { leucocyte } \\
\text { isotope scan }\end{array}$ & Angiography & Treatment & $\begin{array}{l}\text { Recurrence } \\
\text { (No of } \\
\text { strictures) }\end{array}$ & $\begin{array}{l}\text { No of } \\
\text { laparotomies }\end{array}$ & $\begin{array}{l}\text { Interval } \\
\text { between first } \\
\text { treatment and } \\
\text { recurrence }(y)\end{array}$ & $\begin{array}{l}\text { Follow } \\
\text { up (y) }\end{array}$ \\
\hline 1 & $M / 29$ & 5 & Subocclusion & $\mathrm{J}$ & 3 & ND & Normal & $\begin{array}{l}\text { Surgery, } \\
\text { steroid therapy }\end{array}$ & $+(1)$ & 3 & 3.5 & 17 \\
\hline 2 & $\mathrm{M} / 39$ & 5 & $\begin{array}{l}\text { Subocclusion, } \\
\text { diarrhoea }\end{array}$ & $\mathrm{J}+\mathrm{I}$ & 8 & ND & ND & Surgery & - & 1 & - & 26 \\
\hline 3 & $F / 36$ & 1 & Subocclusion & $\mathrm{J}$ & 2 & ND & ND & Surgery & - & 1 & - & 2 \\
\hline 4 & $\mathrm{M} / 50$ & $?$ & $\begin{array}{l}\text { Subocclusion, } \\
\text { diarrhoea }\end{array}$ & I & 4 & ND & ND & - & - & 0 & - & $\begin{array}{c}0 \\
\text { (death) }\end{array}$ \\
\hline 5 & $\mathrm{~F} / 70$ & 0.5 & Subocclusion & $\mathrm{J}$ & 4 & $\begin{array}{l}\text { Jejunum } \\
\text { uptake }\end{array}$ & ND & $\begin{array}{l}\text { Surgery, } \\
\text { mesalazine }\end{array}$ & $+(2)$ & 1 & 1 & 2 \\
\hline 6 & $M / 49$ & 4 & Subocclusion & $\mathrm{J}+\mathrm{I}$ & 17 & ND & ND & $\begin{array}{l}\text { Surgery, } \\
\text { steroid therapy }\end{array}$ & + & 1 & 2 & 16 \\
\hline 7 & $M / 36$ & 7 & Subocclusion & $\mathrm{J}+\mathrm{I}$ & 24 & ND & ND & $\begin{array}{l}\text { Balloon } \\
\text { endoscopic } \\
\text { dilatation }\end{array}$ & + & 1 & $<1$ & 1.5 \\
\hline 8 & $M / 15$ & 5 & Subocclusion & $\mathrm{J}+\mathrm{I}$ & 5 & ND & $\begin{array}{l}\text { Stenosis, } \\
\text { aneurysms }\end{array}$ & Surgery & + & 1 & 11 & 15 \\
\hline 9 & $M / 35$ & 7 & Subocclusion & $\mathrm{J}$ & 6 & ND & ND & $\begin{array}{l}\text { Surgery, } \\
\text { steroid therapy }\end{array}$ & $\begin{array}{l}+ \\
(3+1+1)\end{array}$ & 4 & 2 & 30 \\
\hline 10 & $F / 65$ & 12 & Subocclusion & I & 7 & ND & Aneurysms & Surgery & - & 1 & - & 4 \\
\hline $11^{1}$ & $\mathrm{~F} / 34$ & 11 & Subocclusion & $\mathrm{J}+\mathrm{I}$ & 14 & $\begin{array}{l}\text { Jejunum } \\
\text { uptake }\end{array}$ & $\begin{array}{l}\text { Stenosis, } \\
\text { aneurysms }\end{array}$ & $\begin{array}{l}\text { Surgery, } \\
\text { steroid } \\
\text { therapy, } \\
\text { azathioprine, } \\
\text { methotrexate }\end{array}$ & + & 2 & $<1$ & 6 \\
\hline 12 & $\mathrm{~F} / 47$ & 8 & Subocclusion & I & 5 & ND & ND & Surgery & $+(1)$ & 2 & 4 & 6 \\
\hline
\end{tabular}

—, not applicable; +, present; ?, unknown; ND, not done; J, jejunum; I, ileum; HMPAO, hexamethyl propylene amine oxime.

${ }^{1}$ Previously reported. ${ }^{11}$

Table 2 Extradigestive characteristics of patients with cryptogenetic multifocal ulcerous stenosing enteritis

\begin{tabular}{|c|c|c|c|}
\hline $\begin{array}{l}\text { Case } \\
\text { No }\end{array}$ & Extradigestive symptoms & $\begin{array}{l}\text { Interval between } \\
\text { first digestive } \\
\text { symptoms and } \\
\text { extradigestive } \\
\text { involvement }(y)\end{array}$ & Outcome of extradigestive symptoms \\
\hline 1 & $\begin{array}{l}\text { Obstructive pulmonary } \\
\text { syndrome }\end{array}$ & +10 & $\begin{array}{l}\text { Remission with corticosteroid therapy } \\
\text { and salbutamol }\end{array}$ \\
\hline 1 & $\begin{array}{l}\text { Symetrical sensory } \\
\text { neuropathy of legs }\end{array}$ & +14 & Remission with corticosteroid therapy \\
\hline 3 & Arterial hypertension & +2 & Remission with perindopril \\
\hline 4 & Periaxial neuropathy & 0 & Stable \\
\hline 5 & Atrial fibrillation & -5 & $\begin{array}{l}\text { Failure of electric cardioversion; long } \\
\text { term digoxin therapy }\end{array}$ \\
\hline 5 & Oral aphthae & 0 & Spontaneous remission \\
\hline \multirow[t]{4}{*}{11} & Raynaud's phenomenon & & Remission with corticosteroid therapy \\
\hline & Joint pain & & Remission with corticosteroid therapy \\
\hline & Sicca syndrome & & Remission with corticosteroid therapy \\
\hline & $\begin{array}{l}\text { Obstructive pulmonary } \\
\text { disease }\end{array}$ & & Remission with corticosteroid therapy \\
\hline
\end{tabular}

lymphoma, tuberculosis) or receiving drugs known to injure the small intestine (nonsteroidal anti-inflammatory drugs, enteric coated aspirin with epinephrine or pseudoephedrine, and potassium chloride) were excluded. All medical files were reviewed. The criteria for CMUSE were: intermittent bouts of intestinal obstruction, clinical proof of stenoses of the small intestine which laparotomy showed to be staggered, multiple, and plurifocal; and lesions recognised at surgery and at microscopic examination as being of an inflammatory nature with ulceration of the mucous membrane of the intestine. ${ }^{2-9}$ Twelve patients fulfilled the criteria for CMUSE and were included in the study.

\section{Results}

We studied 12 patients (seven males, five females). Digestive characteristics are summarised in table 1 and extradigestive features in table 2 .
CLINICAL CHARACTERISTICS

Patients were aged $15-70$ years with a mean age of 42.1 (4.4) years when CMUSE was diagnosed. All patients were hospitalised between 1965 and 1993. All had bouts of abdominal pain, vomiting, and subocclusion. Weight loss in two months was more than $4 \mathrm{~kg}$ in all patients. Mean time between the first intestinal symptoms and small bowel stricture diagnosis was 6.0 (1.1) years, ranging from six months to 12 years.

Extradigestive symptoms occurred in five patients (table 2). Two patients had an obstructive pulmonary syndrome which occurred seven and 10 years after the first digestive symptoms and was partially reversible with salbutamol. One of these patients also developed joint pain (left elbow, and wrist with intra-articular swelling), a sicca syndrome, and Raynaud's phenomenon. Neurological involvement occurred in two patients: one patient had symmetrical sensory neuropathy of the legs with a normal electromyogram and neuromuscular biopsy; the other patient had a periaxial neuropathy. Arterial hypertension occurred in one case (diastolic blood pressure $105 \mathrm{~mm} \mathrm{Hg}$ ) and atrial fibrillation in one. One patient had oral aphthae but no other symptoms of Behçet's syndrome; in particular, there were no ocular signs or cutaneous symptoms.

\section{LABORATORY FINDINGS}

No biological signs of inflammation were found in any case. Erythrocyte sedimentation rate was normal in all cases. $\mathrm{C}$ reactive protein was assayed in three patients and was found to be normal. No patient had proteinuria or haematuria. Liver function tests and creatinine were normal. Rheumatoid factors, antinuclear, anti-ds-DNA, anti-ss-DNA, anti-nRNP, antiSSA, anti-SSB, antimicrosomal, antismooth 
muscle, antimitochondrial, antigliadin, and antineutrophil cytoplasmic antibodies were negative in five of five tested patients. Serological tests for hepatitis B virus, hepatitis $\mathrm{C}$ virus, and human immunodeficiency virus were performed in five, two, and three cases, respectively, and were negative.

Classical pathway complement activity $(\mathrm{CH} 50)$ was tested in two patients and was moderately decreased $(75 \%$ of mean normal level obtained with a pool of 100 normal plasma specimens) in one previously reported patient. ${ }^{11}$ The functional activity of component C2 in plasma was very low $(16 \%)$ whereas plasma immunochemical levels of C3 and C4 were normal. Low plasma levels of $\mathrm{C} 2$ were related to the presence of heterozygous type I C2 deficiency, as shown by identification of a 28 base pair deletion in the sixth exon of the C2 gene using polymerase chain reaction amplification and specific primers. ${ }^{12}$

\section{MORPHOLOGICAL FEATURES}

Plain radiographs of the abdomen were normal in all patients.

Small bowel series were performed in 12 patients and showed multiple short stenoses located in the jejunum and proximal ileum in all cases. These stenoses were short, regular, and sometimes ulcerated. The number of stenoses was underestimated in comparison with laparotomy. Between the strictures, the small intestine was dilated but normal, without evidence of mucosal involvement. There were no fistulas.

Gastroscopy and colonoscopy were performed in six patients and were normal. Duodenal biopsies were normal. In particular, there was no villous atrophy. A jejunoscopy was carried out in one patient and showed jejunal ulcerous strictures. Jejunoscopy was also performed in another patient one year after surgical resection of the strictures but was normal.

Selective coeliac and mesenteric angiography was performed in four patients. In one patient, the first angiogram showed stenosis with poststenotic dilatation of the large jejunoileal arteries. One year later, angiography revealed alterations in the distal jejunal arteries with the presence of aneurysms (fig 1); the suprarenal arteries were normal. Angiography in the other patients showed aneurysms of the distal jejunal arteries in two cases and stenosis of the large jejunoileal arteries in one. One angiogram was normal.

Two bowel isotope scans using ${ }^{99 \mathrm{~m}} \mathrm{Tc}$ HMPAO labelled leucocytes revealed uptake in the distal jejunum.

\section{PATHOLOGICAL FEATURES}

Macroscopic examination of the small intestine was performed in all patients. The digestive lesions of CMUSE were characteristic (fig 2). The number of strictures ranged from two to 25 (mean 8.3 (1.9)). They were short, measuring $1-2 \mathrm{~cm}$ in thickness, and separated by $2-10$ $\mathrm{cm}$ of normal mucosa. In nine patients the strictures were located in the jejunum and in eight in the proximal ileum. In all patients some

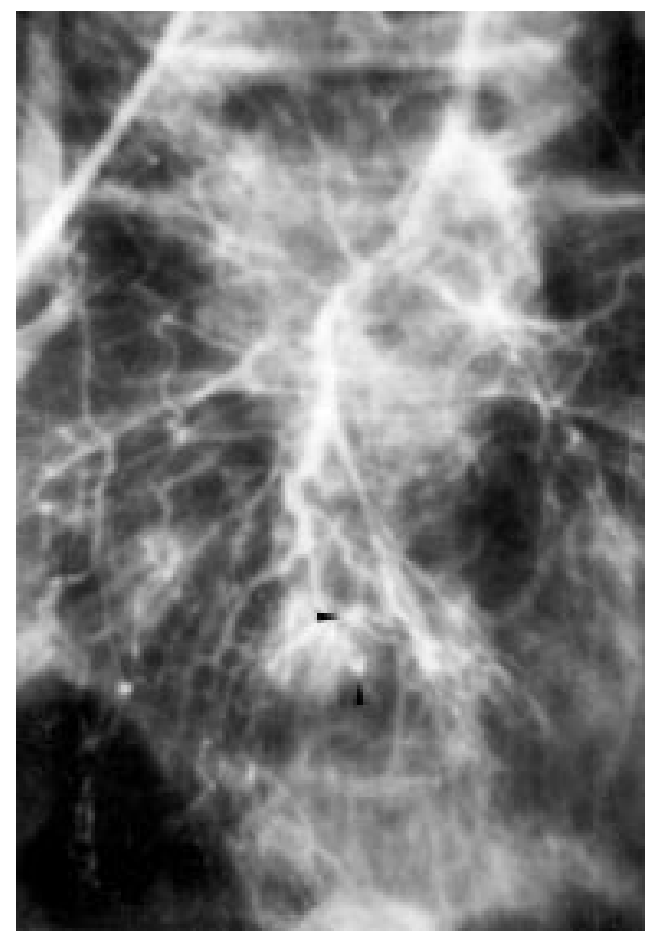

Figure 1 Superior mesenteric artery. Selective conventional angiography; arterial phase showing aneurysms of the distal jejunal arteries (arrowheads).

of the stenoses were ulcerated. The remainder of the small intestine was normal.

Small bowel pathology was performed in all patients but one. In all cases, some of the stenoses were associated with central ulceration and covered by fibrin and neutrophils with an inflammatory infiltrate consisting of monocytes and neutrophils. In seven patients the inflammatory infiltrate contained eosinophils. The mucosa on both sides of the ulcerations was histologically normal. The ulcerations were superficial, affecting the mucosae and the submucosae, but did not extend into the underlying tissues. Fibrosis and inflammatory infiltrate extended beyond the ulcerations. The submucosae was thickened by fibrosis but the muscular coat was nearly normal. There was no lymphadenopathy, giant cell granulomas, or aphthoid or fissural ulceration. Vessels examination was available in these seven patients. Small sized arteries were normal. Thickening, inflammatory infiltrate, thrombosis, and endophlebitis were present on venules in four cases.

TREATMENT AND OUTCOME (TABLE 1)

Treatment consisted of surgical resection of the small bowel strictures in 10 cases and balloon endoscopic dilatation in one. One patient was not treated and died from septic shock. Mean follow up after surgery was 125 (35) months (range 10-360). There were three complete recoveries without recurrence of clinical symptoms. Seven patients had digestive recurrence with abdominal pain, weight loss, and vomiting after surgery. Among these seven cases, two also had extradigestive symptoms including fever, polyarthralgia, and sicca syndrome. A second laparotomy was necessary because of recurrence of strictures in four patients, a third 


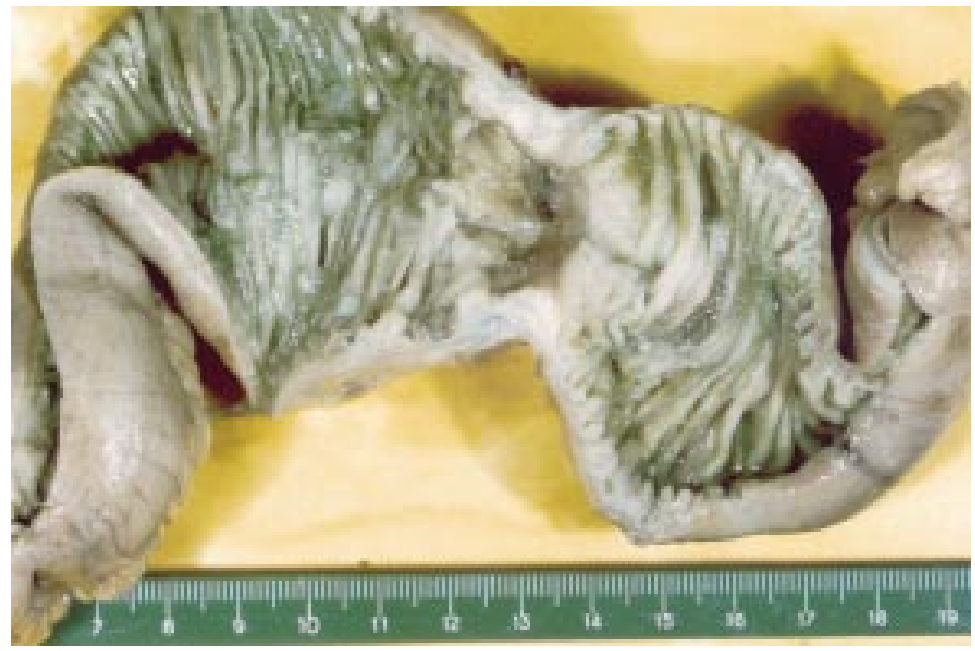

Figure 2 Longitudinal section of the resected small bowel through the strictures.

in one case, and a fourth in one case. The new strictures were located directly above the anastomosis. Treatment with prednisone (30 or 50 $\mathrm{mg}$ /day) was initiated in four patients because of recurrence of abdominal pain and vomiting despite surgical resection of the strictures. These patients had already undergone four, three, two, and one laparotomy. Abdominal pain and vomiting resolved in less than one month. The two steroid treated patients with extradigestive symptoms - that is, joint pain and symmetrical sensory neuropathy of the legs-also showed resolution of these symptoms. Steroid therapy lasted 1-2 years in three patients. One patient was receiving a low dose $(10 \mathrm{mg} /$ day $)$ of prednisolone after 10 years of steroid therapy. As steroid therapy was tapered off, abdominal pain reappeared in all patients but only one showed radiological evidence of stricture recurrences. No new laparotomy was necessary in steroid treated patients. Other medical treatments were azathioprine, methotrexate. and mesalamine but none caused remission of abdominal pain.

\section{Discussion}

The clinical, biological, morphological, and histological features of our patients correspond with the criteria of Debray et al for CMUSE. ${ }^{2}$ To the best of our knowledge, only 17 cases of chronic multiple ulcerations compatible with CMUSE $^{2-11}$ have been reported, the largest series including six patients. ${ }^{8}$ In our first reported case, ${ }^{11}$ we suggested that CMUSE may be due to vasculitis with mainly intestinal expression. To confirm this hypothesis and to suggest a strategy of treatment, we tried to regroup all French cases of CMUSE. All patients complained of intestinal symptoms and half had extraintestinal symptoms. There was no biological signs of an inflammatory syndrome.

The small intestinal radiographs in our study were comparable with those observed in the previously reported cases: number and localisation of stenoses, and normality of the remaining small intestine. Selective coeliac and mesenteric angiography was performed in four patients; one patient underwent angiography twice. Angiography was abnormal in four cases; stenosis of the jejunoileal arteries was observed in two cases and aneurysms in three. Small bowel pathology showed that all ulcerations had the same characteristics: superficial lesions affecting the mucosae and submucosae but without extension into the underlying tissues. They were associated with an inflammatory infiltrate containing eosinophils. In addition to the three patients with abnormal angiograms, four presented inflammatory infiltrate, thrombosis, and endophlebitis on venules, suggesting that at least seven patients had vascular abnormalities. Although nonspecific, stricture, ulceration features, and vessels abnormalities were highly suggestive of a vascular disorder. ${ }^{13}$

Surgical resection of patient strictures was often followed by recurrent stricturing proximal to the anastomosis. In two patients the isotope scans using labelled leucocytes were positive. These data could indicate a diagnosis of Crohn's disease, which could not be definitively excluded. However, the intestinal lesions of CMUSE are different from those observed in Crohn's disease. Features not suggestive of Crohn's disease include the shortness of the strictures and the absence of an inflammatory syndrome at any time during the clinical course, transmural or aphthoid ulcerations, and giant cell granulomas on the resected small bowel. After several years of evolution, no patient developed intestinal perforation, fistulisation, or other localisations of the disease, despite several recurrences. Moreover, coeliac and mesenteric angiographic abnormalities in Crohn's disease are very rare and different from those observed in our patients. ${ }^{14}$ Wakefield et al have suggested that Crohn's disease might be a consequence of an intestinal vasculitis ${ }^{15}$ but in this disease the abnormal vessels are located in the muscularis mucosae while they were found in the mucosae and submucosae in our patients.

Our patients did not have chronic ulcerative non-granulomatous jejunitis or coeliac disease because of the absence of villous atrophy, malabsorption, and antigliadin antibodies. Nevertheless, overlap syndromes are possible ${ }^{1}$ : deep ulcerations often associated with stenoses have been described. ${ }^{16}$ Tuberculosis ${ }^{17}$ and drug related stenoses ${ }^{18}$ were eliminated by our questionnaire and by verifying patient files. As our patients had an unusual disease, they were carefully investigated and it is unlikely that they had drug related strictures. Patients with oral aphthae did not have any other symptoms of Behçet's syndrome.

An interesting feature in our patients was their dramatic response to corticosteroid therapy. The response to corticosteroids in patients with idiopathic non-granulomatous chronic enterocolitis seems to differ in different studies. Baer and colleagues ${ }^{19}$ reported that only $15 \%$ of patients treated with corticosteroids experienced a lasting benefit. In contrast, $78 \%$ of patients reported by Ruan and colleagues $^{16}$ derived long term benefit. This variability probably reflects the heterogeneous 
nature of the causes of chronic ulcerative nongranulomatous jejunitis. ${ }^{20}$

Abnormalities on angiography, ${ }^{2122}$ scintigraphic uptake of HMPAO labelled leucocytes in the small intestine, ${ }^{23}$ pathological lesions of the small intestine, ${ }^{24}$ steroid sensitivity, steroid dependence, and extradigestive involvement are strong criteria that must be taken into consideration in the diagnosis of a systemic inflammatory disease, ${ }^{22}$ despite the absence of biological signs of inflammation. As this was a retrospective study, it was possible to look for complement C2 deficiency in only two patients. Certain disease such as juvenile rheumatoid arthritis and chronic glomerulonephritis seem to be associated with heterozygous $\mathrm{C} 2$ deficiency. ${ }^{25}$ Insufficient binding of C4 or C2 to circulating immune complexes in deficient patients may explain the frequent association of deficiencies of classical pathway proteins with immune complex disease. We speculate that partial C2 deficiency rendered patients more susceptible to vasculitis. Definite evidence of vasculitis with necrosis of medium and small arteries is rarely found at small bowel pathology. ${ }^{21}$ The lack of microscopic vasculitis in our patients could have been caused by localisation of vascular disorders on large jejunoileal arteries which are not always studied on the resected small bowel. This hypothesis may also explain the absence of clearcut vasculitis at pathological examination of the previously reported cases. ${ }^{2-1124}$

Gastrointestinal manifestations of small intestine vasculitis usually include abdominal pain, diarrhoea, bleeding, ulceration, and perforation. ${ }^{21}{ }^{26}$ Strictures are rare but have also been reported. ${ }^{27} 28$ Aneurysms observed at angiography are suggestive of polyarteritis nodosa $^{22}$ even if they are not entirely specific. ${ }^{29}{ }^{30}$ Gastrointestinal involvement occurs in up to $50 \%$ of patients with polyarteritis nodosa and may be the only manifestation in up to $36 \%$ of cases. $^{27}{ }^{31}$ Signs may vary from mild abdominal tenderness to intra-abdominal catastrophe. Ulceration may occur anywhere along the gastrointestinal tract, including the jejunum. ${ }^{32}$ There is apparently no correlation between clinical manifestations or arteriographic findings and the development of intraabdominal complications but patients with severe disease are more likely to have abnormal visceral arteriograms. ${ }^{27}$ Nevertheless, none of our patients corresponded to the American College of Rheumatology's criteria ${ }^{30}$ or to Fauci's classification ${ }^{22}$ of polyarteritis nodosa. According to the most recent nomenclature of systemic vasculitides, ${ }^{33}$ polyarteritis nodosa is characterised by absence of vasculitis in arterioles, venules, or capillaries. It affects medium sized arteries and may cause the abnormalities seen in the angiograms of our patients. On the other hand, microscopic polyangiitis affects arterioles, venules, or capillaries. The pathological manifestations of our patients showed venular involvement compatible with vasculitis. ${ }^{33}$ Despite the absence of direct demonstration of a pathological process, clinical, radiological, and pathological manifestations in some patients may be related to vasculitis or a vasculitis-like disease.

In conclusion, our 12 patients had a distinct clinical syndrome that could not be classified into any previously recognised category and which was characterised by inflammation of the small intestine. CMUSE is often unrecognised, as shown by the long mean time between the first symptoms and diagnosis of strictures. This study confirms our earlier hypothesis that CMUSE is characterised by steroid sensitive inflammation of the small bowel which often recurs after surgery. Coeliac and mesenteric angiography and pathological examination of the small bowel are suggestive of a vascular disorder. CMUSE could be added to the list of vasculitis or diseases mimicking vasculitis. Eliminating strictures seems essential to alleviate symptoms. Surgery is followed by recurrence of digestive symptoms in about $50 \%$ of cases and by recurrence of strictures in $50 \%$. Balloon dilatation could be a good option to prevent extended resection of the small bowel. Corticosteroid therapy may prevent recurrent laparotomies but often leads to dependence.

The authors thank Gérard Gay, Jean-Charles Delchier, Marc-André Bigard, Alexandre Pariente, Denis Goldfain, Daniel Sontag, Jean-Pierre Chagnon, Marc Cerf, Jacques Lescut, Pierre Coutarel, and Jean-Pierre Gendre who provided one patient each.

1 Jeffries GH, Steinberg H, Sleisenger MH. Chronic ulcerative (nongranulomatous) jejunitis. Am F Med 1968;44:4759

2 Debray C, Besançon F, Hardoin JP, et al. Entérite sténosante ulcéreuse plurifocale cryptogénétique. Arch Fr Mal App Dig 1964;53:193-206.

3 Rocha A, Artigas V. La maladie ulcéreuse sténosante du jéjuno-iléon. Arch Fr Mal App Dig 1959;10:1230-6.

4 Gauthier AP, Rampal M, Lieutaud R, et al. Sténoses multiples "idiopathiques" de l'intestin grêle. A propos de deux observations. Arch Fr Mal App Dig 1966;55:31-43.

5 Paille F, Champigneulle B, Brucker P, et al. L'entérite sténosante ulcéreuse plurifocale cryptogénétique. A propos de deux observations. Ann Gastroenterol Hepatol 1981;17: 405-9.

6 Macinot C, Lorenzini C, Ravey $M$, et al. Entérite segmentaire sténosante plurifocale. Semin Hop Paris 1974; $0: 2518-20$

7 Lescut J, Grégoire L, Weisemburger JP. Sténoses multiples cryptogénétiques de l'intestin grêle. (A propos d'une nouvelle observation). Lille Med 1969;14:602-6.

8 Chagnon JP, Devars du Mayne JF, Marche C, et al. L'entérite sténosante ulcéreuse multifocale cryptogénétique: une entité autonome? Gastroenterol Clin Biol 1984;8:808-13.

9 Doutre LP, Paccalin J, Périssat J, et al. Entérite sténosante ulcéreuse plurifocale. Une nouvelle observation. Arch Fr Mal App Dig 1966;55:537-40.

10 Harrop Shoesmith J, Tate GT, et al. Multiple strictures of the jejunum. Gut 1964;5:132-5.

11 Perlemuter G, Chaussade S, Soubrane O, et al. Multifocal stenosing ulcerations of the small intestine revealing vasculitis associated with C2 deficiency. Gastroenterology 1996; 100: $1628-32$.

12 Johnson CA, Densen P, Hurford RK, et al. Type I human complement C2 deficiency; a 28-base pair deletion causes skipping of exon 6 during RNA splicing. F Biol Chem 1992; skipping of exon

13 Lewin KJ, Riddell RH, Weinstein WM. Vascular disorders. In: Gastrointestinal pathology and its clinical implications. New In: Gastrointestinal pathology and it
York: Igaku-Shoin, 1992:37-68.

York: Igaku-Shoin, 1992:37-68.
14 Brahme F, Hildell J. Angiography in Crohn's disease revisited. Am f Roentgenol 1976;5:941-51.

5 Wakefield AJ, Dhillon AP, Rowles PM, et al. Pathogenesis of Crohn's disease: multifocal gastrointestinal infarction. Lancet 1989;2:1057-62.

16 Ruan AE, Komorowski RA, Hogan WJ, et al. Nongranulomatous chronic idiopathic enterocolitis: clinicopathologic profile and response to corticosteroid. Gastroenterology 1996;11:629-37.

17 Tandon MD, Prakash A. Pathology of intestinal tuberculosis and its distinction from Crohn's disease. Gut 1972;13:2609.

18 Lang J, Price AB, Levi AJ, et al. Diaphragm disease: pathology of disease of the small intestine induced by nonsteroidal anti-inflammatory drugs. F Clin Pathol 1988;41: 516-26.

19 Baer AN, Bayless TM, Yardley JH. Intestinal ulceration and malabsorption syndromes. Gastroenterology 1980;79:754-65. 
20 Mills PR, Brown IL, Watkinson G. Idiopathic chronic ulcerative enteritis. Report of five cases and review of the ulcerative enteritis. Report of five case
literature. $O \mathcal{F}$ Med 1980;194:133-49.

21 Camilleri M, Pusey CD, Chadwick VS, et al. Gastrointestinal manifestations of systemic vasculitis. $Q \mathcal{F ~} \mathrm{Med}$ 1983;206:141-9.

22 Fauci AS, Haynes BF, Katz P. The spectrum of vasculitis Clinical, pathologic, immunologic, and therapeutic considerations. Ann Intern Med 1978;89:660-76.

23 Schölmerich J, Schmidt E, Schümichen C, et al. Scintigraphic assessment of bowel involvement and disease activity in Crohn's disease using technetium 99m-hexamethyl propylene amine oxine as leukocyte label. Gastroenterology 1988;95:1287-93.

24 Lie JT Vasculitis, 1815 to 1991: classification and diagnostic specificity. F Rheumatol 1992;19:83-8.

25 Agnello MD. Complement deficiency states. Medicine 1978; 57:1-23.

26 Williams DH, Kratka CD, Bonafede JP, et al. Polyarteritis nodosa of the gastrointestinal tract with endoscopically nodosa of the gastrointestinal tract with endoscopically Endosc 1992;38:501-3.
27 McCauley RL, Johnston MR, Fauci AS. Surgical aspects of systemic necrotizing vasculitis. Surgery 1985;97:104-9.

28 Kuehne SE, Gauvin GP, Shortsleeve MJ. Small bowel stricture caused by rheumatoid vasculitis. Radiology 1992;184: 215-16.

29 Herali P, Kajander H, Pajari R, et al. Diagnostic significance of angiographically observed visceral aneurysm with regard to polyarteritis nodosa. Acta Radiol 1991;32:143-8.

30 Lightfoot RW Jr, Michel BA, Bloch DA, et al. The American College of Rheumatology 1990 criteria for the classification of polyarteritis nodosa. Arthritis Rheum 1990;33:1088-93.

31 Williams DA, Kratka CD, Bonafede JP, et al. Polyarteritis nodosa of the gastrointestinal tract with endoscopically documented duodenal and jejunal ulceration. Gastrointest Endosc 1992;38:501-3.

32 Lopez L, Schocket A, Stanford R, et al. Gastrointestinal involvement in leukocytoclastic vasculitis and polyarteritis nodosa. F Rheumatol 1980;5:677-87.

33 Jennette JC, Falk RJ, Andrassy K, et al. Nomenclature of systemic vasculitides. Proposal of an international consensus conference. Arthritis Rheum 1994;37:187-92. 